\title{
Tranexamic acid for reducing blood loss following vaginal delivery: a double-blind randomized controlled trial
}

\author{
Francis Nwabueze Igboke ${ }^{1 *}$, Vitus Okwuchukwu Obi ${ }^{1}$, Benedict Ikechukwu Dimejesi ${ }^{1}$ and \\ Lucky Osaheni Lawani
}

\begin{abstract}
Background: Postpartum haemorrhage (PPH) is a major cause of maternal morbidity and mortality worldwide. Tranexamic acid (TXA) is a useful drug for prevention of PPH and merits evaluation in Nigeria, where PPH is the leading cause of maternal death (25\%) and severe maternal morbidity. This study evaluates the efficacy of TXA in reducing blood loss following vaginal delivery.

Methods: This was a double-blind randomized placebo-controlled study on the efficacy and safety of intravenous TXA in reducing blood loss in women undergoing vaginal delivery in a tertiary hospital. Data analysis was conducted with IBM SPSS software (version 20, Chicago II, USA). P-value $<0.05$ was considered statistically significant.

Results: The mean estimated blood loss was lower in TXA compared with the placebo group. (174.87 $\pm 119.83 \mathrm{ml}$ versus $341.07 \pm 67.97 \mathrm{ml}$ respectively; $P<0.0001$ ). PPH (blood loss $>500 \mathrm{ml}$ ) was $5.13 \%$ in the study arm compared to the control arm 7.14\%- risk ratio (RR) $0.71 ; 95 \% \mathrm{Cl}: 0.38-1.79, p=0.5956]$. Additional uterotonics was required more in the control group compared to the treatment group $14(16.67 \%)$ versus $3(3.85 \%), p$-value $=0.007$. There were no major complications noticed in the treatment group.

Conclusion: This study demonstrated that intravenous administration of TXA reduced blood loss following vaginal delivery. It also reduced the need for additional uterotonics. However, blood loss greater than 500 was not significantly reduced.
\end{abstract}

Trial registration: This trial was registered retrospectively.

Pan African Clinical Trial Registry: PACTR202010828881019 on 12/10/2020.

Keywords: Tranexamic acid, Postpartum haemorrhage, Blood loss, Vaginal delivery, Prevention

\section{Background}

Globally, about 500,000 women die yearly from complications of pregnancy and childbirth [1]. Majority of these deaths occur in the immediate postpartum period and in most cases are due to postpartum haemorrhage $(\mathrm{PPH})[2,3] . \mathrm{PPH}$ is the commonest cause of

\footnotetext{
*Correspondence: igbokefrancisn@gmail.com

${ }^{1}$ Alex-Ekwueme Federal University Teaching Hospital, Abakaliki, Nigeria

Full list of author information is available at the end of the article
}

maternal death, with the highest incidence in low-middle-income countries (LMIC) $[1,4]$. Moreover, postpartum haemorrhage $(\mathrm{PPH})$ is the main cause of severe maternal morbidity (SMM), accounting for $47.6 \%$ of the cases of SMM [5, 6]. PPH is the excessive bleeding per vaginam after the delivery of the baby and up to six weeks postpartum [1]. It can either be primary or secondary $[6,7]$. Primary PPH is the loss of $>500 \mathrm{mls}$ of blood within the first $24 \mathrm{~h}$ of delivery or loss of any amount that is enough to cause haemodynamic 
instability $[7,8]$. Primary PPH complicates approximately $3 \%$ of vaginal deliveries [9].

In many cases of PPH, the true blood loss is often underestimated due to problems with visual blood estimation [10-12]. The risk of severe maternal morbidity and death from PPH depends on the amount and rate of blood loss, as well as the clinical state of the woman [10], such that blood loss of as little as $200 \mathrm{ml}$ could be life-threatening in woman with severe anaemia or cardiac disease [13]. The risk factors for PPH includes previous $\mathrm{PPH}$, primiparity, prolonged or augmented labour, multiple pregnancy, previous caesarean delivery, polyhydramnios, and macrosomia [14]. Nevertheless, most women with PPH have low-risk pregnancies and no identifiable risk factors. It is therefore important to prevent PPH in all women [15].

The interval between delivery and placental expulsion is a critical window for the prevention of $\mathrm{PPH}$ [16]. Oxytocics and anti-fibrinolytic like Tranexamic acid (TXA) are effective in prevention and treatment of $\mathrm{PPH}$ [17-19]. Active management of the third stage of labour (AMTSL) as one of the strategies for the prevention of $\mathrm{PPH}$. It comprises of the administration of uterotonic agents after delivery of the baby, delayed cord clamping and cutting and controlled cord traction (CCT) [20-23]. In addition to this enhancement of mechanical haemostasis, a supportive biochemical haemostatic effect might also be expected from the complementary use of prohaemostatic drugs such as TXA in the prevention of PPH [24].

Tranexamic acid is a potent antifibrinolytic agent that exerts its effect by blocking lysine binding sites on plasminogen molecules preventing the breakdown of blood clot (fibrinolysis) and resulting in hemostasis [24]. Previous trials have shown that TXA in planned surgery reduces the risk of blood transfusion, mean transfused volume, and need for re-operation due to bleeding without safety concerns [25, 26]. Furthermore, considerable decrease in mean menstrual blood loss have been reported in women with menorrhagia treated with TXA, in contrast to control or placebotreated women [27-29]. A randomized controlled trial (RCT) involving studies in high-income countries demonstrated the efficacy of TXA in prevention of PPH [30]. However, the authors reports that small sample size was a limitation of the study. Therefore, there is need for adequately powered studies with larger representative sample size, especially in a low resource setting like Nigeria. The present study aims to evaluate the efficacy and safety of TXA in prevention of $\mathrm{PPH}$ and associated SMM after vaginal deliveries in a Nigerian setting.

\section{Methods}

\section{Study design}

This was a double-blind randomized placebo-controlled study on the efficacy and safety of intravenous TXA in reducing blood loss in women undergoing vaginal delivery at a tertiary hospital in southeast Nigeria and who met the inclusion criteria after obtaining an informed consent. The study was conducted from June 2018 to December 2019. The study was approved by the Human Research and Ethics Committee (HREC) of AlexEkwueme Federal University Teaching Hospital, Abakaliki (FETHA/REC/VOL1/2017/541).

This study was registered with Pan African Clinical Trial Registry: PACTR202010828881019.

\section{Study setting}

The study was conducted in the department of Obstetrics and Gynaecology, Alex-Ekwueme Federal University Teaching Hospital, Abakaliki (AEFUTHA), Nigeria. The department manages both low and high-risk pregnant women using standardized protocols.

\section{Participants}

The participants for this study were from the population of women within the reproductive age group undergoing vaginal delivery at the Alex-Ekwueme Federal University Teaching Hospital, Abakaliki who met the inclusion criteria after obtaining an informed consent.

The inclusion criteria include spontaneous labour in booked patients, planned vaginal delivery, term pregnancy, singleton pregnancy and cephalic presentation, parturient who have no contraindications to the use of tranexamic acid and informed consent form signed. Women with prior history of thromboembolism, autoimmune diseases, sickle cell disease, bleeding disorders, renal disease, liver pathology, known cardiovascular disease, multiple pregnancy, intrauterine fetal death, previous uterine surgeries, patients with chronic hypertension, preeclampsia, eclampsia, HELLP syndrome, antepartum haemorrhage, ruptured uterus, varicose veins at increased risk of deep vein thrombosis, history of epilepsy/seizures and those that had episiotomy were excluded.

\section{Sample size}

The minimum sample size was determined using the formula for comparison between two groups when the end point is a quantitative data [31].

$$
\text { Sample size }=2 \operatorname{SD}^{2}\left(Z_{\alpha / 2}+Z_{\beta}\right)^{2} / \mathrm{d}^{2}
$$


Where:

SD: Standard deviation of blood loss for treatment group was 32.4; derived from a pilot study conducted on use of tranexamic acid in prevention of postpartum haemorrhage in a similar population of women who had caesarean section at the study centre (AEFUTHA).

$\mathrm{Z}_{\alpha / 2}: 1.96$ (from $\mathrm{Z}$ table) at type 1 error of $5 \%$

$Z_{\beta}$ : To increase accuracy of the study, $90 \%$ power was used $=1.282$ (from $Z$ table).

d: Standardized effect size (difference in mean value between 2 groups- Sentilhes et. al) $=236.9$ (placebo arm) -220.3 (treatment arm) [6]=16.6.

Sample size per group $=2(32.4)^{2} \times(1.96+1.282)^{2}$ / $(16.6)^{2}=80$

Ten percent $(10 \%)$ of the minimum sample size per group $(10 / 100 \times 80 / 1 \approx 8)$ was added to correct for any attrition hence the final sample size was 88 for each arm.

\section{Randomization and concealment}

The participants were randomized by means of a computer-generated random number using the software Research Randomizer ${ }^{\circledR}$. Eighty-eight (88) numbers were randomly generated from a pool of one hundred and seventy-six (1-176) and these numbers were assigned to group A (tranexamic acid group), while the remaining eighty-eight were automatically assigned to group B (the placebo group).

Group A received $1 \mathrm{~g}$ tranexamic acid (Exacyl ${ }^{\circledR}$; Sanofi Aventis Paris France) slowly (over 30-60 s) intravenously, within 2 min after birth and prophylactic oxytocin administration once the cord had been clamped.

Group B received $10 \mathrm{mls}$ of water for injection (Biofem ${ }^{\circledR}$; Juhel Anambra Nigeria) slowly (over 30-60 s), within $2 \mathrm{~min}$ after birth and prophylactic oxytocin administration, once the cord had been clamped. These drugs were sourced from their drug representatives.

Concealment was done in sequentially numbered opaque sealed envelopes (SNOSE) [32]. These numbers $(1-176)$ were inscribed on brown envelopes and a piece of paper with the inscription 'tranexamic acid', or 'placebo' was placed with the respective drug or placebo accordingly inside these envelopes and sealed. The randomization was done by a statistician and an obstetrician, while the concealment was done by a hospital pharmacist without revealing the results to the researchers. All the envelopes were kept in a locker that was made accessible to all the members of the research team.

Participants that met the inclusion criteria having signed the informed consent form were given sequential study number and the corresponding numbered opaque sealed envelope was allocated to the patient.

\section{Study procedure}

Women were selected for vaginal delivery in the facility and admitted into the labour ward. They were counselled on the study and those who signed the informed consent form were recruited. The antenatal card was retrieved, and highlights reviewed. History was taken and clinical examination was done to confirm the stage of labour while ancillary investigations; haematocrit, haemoglobin and urinalysis were done, and patients were transferred into the labour ward in active phase of labour. The labour was managed actively with the partograph, and augmentation was done as indicated.

The researchers or any of the research assistants took the allotted sealed envelope to the labour ward and handed same over to the labour ward officer who administered the drug or the placebo over 30 to $60 \mathrm{~s}$ within 2 min of delivery of the baby. The envelope with its used content (resealed) was returned to the investigators who kept all the used envelope/packs in a separate locker until the end of the study when un-blinding was done.

AMTSL was carried out for all recruited patients according to departmental protocol (cord clamping, use of oxytocin and controlled cord traction) [30]. Other oxytocics and surgical interventions required to control excessive bleeding were given or done and patients who needed blood transfusion received same.

These interventions were noted. Immediately after the delivery of the baby, when all the liquor were drained, a blood drape (an improvised BRASS-V, a disposable conical, graduated plastic collection bag) was inserted under the patient $[30,33]$. The blood collector drapes were applied in between delivery of the baby to delivery of the placenta/repaired of genital laceration or episiotomy and removed after all events associated with third stage of labour were completed i.e. after the woman is cleaned up and a perineal pad put in place. The blood collected in the blood drape was transferred into a transparent plastic measuring cylinder with a capacity of $500 \mathrm{ml}$, corrected to $2 \mathrm{ml}$ and manufactured by Measure Masters ${ }^{\circledR}$. The blood in the measuring cylinder was read off and documented by the researcher or the assistants. Then, the patient was given pre-weighed pads, which were reweighed $2 \mathrm{~h}$ post-partum [30]. The assessment of blood loss through weighing of sanitary pads within $2 \mathrm{~h}$ of delivery was based on the concept of $4^{\text {th }}$ stage of labour [34], where uterine contractility and hemodynamic status (vital signs) are monitored for $1-2 \mathrm{~h}$ postpartum while the woman is still in the labour and delivery unit. This is the period when the woman is at the greatest risk of primary $\mathrm{PPH}$ and therefore require close monitoring and assessment. For uniformity, the regular labour ward sanitary pad with negligible dry weight was used. EBSA20 electronic weighing scale, which operates at room 
temperature with readability of $20 \mathrm{~kg}$ and $5 \mathrm{~g}$ for maximum and minimum weights respectively, manufactured by the Zhongshan Jimli Electronic Weighing Equipment Co. Ltd was used.

The side effects of the drug were noted. The patients were transferred to the post-natal ward for further observation. The patients' post-delivery pulse rate and blood pressure were noted and recorded [32].

\section{Blood loss estimation}

The estimated blood loss ascertained by measuring the blood collected in the drape and complimented by measuring the weights of the sanitary pads before and after $2 \mathrm{~h}$ of delivery. Immediate post-partum blood loss was calculated thus [32].

Total blood loss $(\mathrm{ml})=$ Blood in the measuring cylinder $(\mathrm{ml})+[$ Pad weight after $2 \mathrm{~h}(\mathrm{gm})$-Pad weight prior to use (gm)]- converted to $\mathrm{ml}$; taking that $1 \mathrm{~g}$ difference in pad weight equals $1 \mathrm{ml}$ of blood [33].

Blood loss greater than $>500 \mathrm{ml}$ was be regarded as excessive bleeding (postpartum haemorrhage).

\section{Follow up}

Patients were expected to stay for $48 \mathrm{~h}$ on admission in the hospital before discharge except otherwise indicated. The duration of stay was dependent on the patient's clinical state. The participants were followed up until discharge from the facility. They were instructed to present to the hospital or reach the researchers or any of the research assistants by phone if they have any unforeseen adverse reaction which was to be reported.

\section{Outcome measures}

Primary outcome measure was estimated blood loss following vaginal delivery (total blood loss following vaginal delivery $=$ estimated blood from cylinder + difference in the weight of pad) [32]. Secondary Outcome Measures include primary PPH following vaginal delivery defined as blood loss $>500 \mathrm{ml}$, need for additional uterotonics to control bleeding, need for blood transfusion (volume and amount) after vaginal delivery, mild maternal side effects (nausea, vomiting, headache, skin rash), major maternal side effects (thromboembolism, maternal death) [35].

\section{Statistical analysis}

Data was collated, tabulated, and statistically analyzed with the Statistical Package for Social Science (IBM SPSS) software (version 20, Chicago II, USA). Continuous variables as the maternal vital signs were presented as means and standard deviations (Mean $\pm 2 \mathrm{SD}$ ), while categorical variables like minor and major side effects were presented as numbers and percentages. Chi-square test $\left(\mathrm{X}^{2}\right)$ was used for comparison between groups for qualitative variables while $\mathrm{t}$-test was used for comparison between groups for quantitative variables. A difference with a $p$-value $<0.05$ was considered statistically significant.

\section{Results}

Over the study period of 6 months, 190 patients were assessed for randomization into the study; 14 were excluded while 176 were allocated to receive either TXA or placebo. Only 78 in the study group and 84 in the control (placebo) group were available for final analysis (Fig. 1).

The demographic characteristics of the participantsmaternal age, parity, gestational age, and height as well as the fetal birth weight are presented in Table 1. The participants were matched to ensure the baseline maternal characteristics between matched pairs were similar.

The mean systolic blood pressure (BP) at presentation, $1 \mathrm{~h}$ and $2 \mathrm{~h}$ post- delivery were not significantly different. Also, the diastolic BP at presentation, $1 \mathrm{~h}$ and $2 \mathrm{~h}$ postpartum as well as the pulse rates between the two groups were not different at these times (Table 2).

The mean duration of application of the blood collection drapes were $28.2 \pm 6.4 \mathrm{~min}$ and $29.4 \pm 5.4 \mathrm{~min}$ for the treatment and placebo groups respectively. The mean estimated blood loss was significantly lower in the TXA group compared with the placebo group $(174.87 \pm 119.83 \mathrm{ml}$ versus $341.07 \pm 67.97 \mathrm{ml}$ respectively; $P<0.0001)$, mean difference of $166.2 \mathrm{ml}(48.7 \%)$. There was no significant statistical difference between the mean haematocrit of the treatment group versus the control group at presentation $(33.99 \pm 3.00$ versus $34.01 \pm 2.92, p=0.9658)$, however, the mean haematocrit between the two groups $48 \mathrm{~h}$ postpartum was statistically different $(32.54 \pm 3.36$ versus $31.33 \pm 2.88$, $p=0.0147$ ). The mean change in haematocrit between the groups $48 \mathrm{~h}$ after delivery was also significantly different $(3.14 \pm 0.94$ versus $4.11 \pm 1.1, p=0.0018)$. The haemoglobin concentration at presentation between the two groups was not significantly different $(11.66 \pm 1.00$ versus $11.84 \pm 0.90$ for treatment and control groups respectively, $p=0.2297$ ). However, the haemoglobin concentration $48 \mathrm{~h}$ after delivery was significantly different $(11.14 \pm 1.07$ versus $10.45 \pm 0.96$ for treatment and control groups respectively, $p=<0.0001)$. There was no significant difference in the platelets and the risk of bleeding between both groups at presentation (Table 3).

Blood loss $>500 \mathrm{ml}$ was not significantly higher in the study group compared to the control group (Risk ratio $(\mathrm{RR})=0.71, \mathrm{CI}[0.38-1.79], p=0.5956$ (Table 4).

There was no significant difference in the blood transfusion received by both groups, $R R=0.25(0.09-2.82)$, $p=0.3496$. Additional uterotonics was required more 


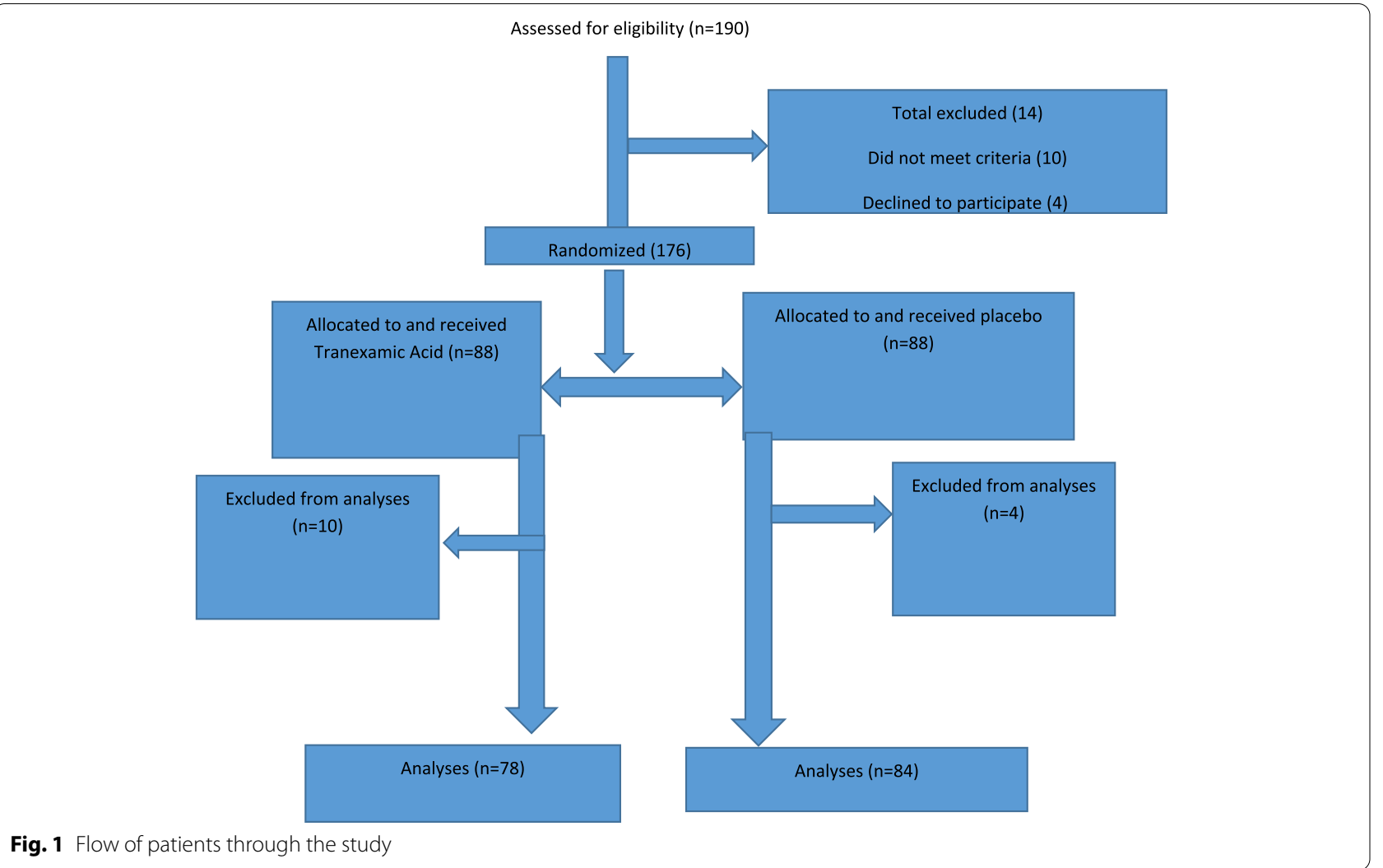

Table 1 Demographic characteristics of the patients

\begin{tabular}{lll}
\hline Variables & $\begin{array}{l}\text { Study group, } \mathbf{N = 7 8} \\
\text { (mean } \pm \text { SD) }\end{array}$ & $\begin{array}{l}\text { Placebo } \\
\text { group, } \mathbf{N}=\mathbf{8 4} \\
\text { (mean } \pm \text { SD) }\end{array}$ \\
\hline Maternal age (years) & $27.95 \pm 5.10$ & $29.95 \pm 3.60$ \\
Gestational age (weeks) & $39.01 \pm 1.38$ & $39.01 \pm 1.33$ \\
Height (metres) & $1.59 \pm 0.05$ & $1.59 \pm 0.06$ \\
Weight (kg) & $78.68 \pm 9.90$ & $80.75 \pm 12.01$ \\
Fetal birth weight (kg) & $3.26 \pm 0.39$ & $3.25 \pm 0.45$ \\
Parity & & 20 \\
0 & 17 & 64 \\
$1-4$ & 61 & \\
\hline
\end{tabular}

in the control group compared to the treatment group, $\mathrm{RR}=0.24(0.12-0.96), p=0.007$ (Table 4).

There were no major complications noticed in the treatment group. However, diarrhoea was noticed only in one patient in that group (Table 4).

\section{Discussion}

In this study, administration of $1 \mathrm{~g}$ intravenous TXA prior to placenta delivery after delivery of the baby was associated with a $48.7 \%(166.2 \mathrm{ml})$ reduction in blood loss at vaginal delivery compared to placebo. This reduction
Table 2 Maternal vital signs at different times before and after delivery

\begin{tabular}{lcc}
\hline Maternal vital signs & Study group, $\mathbf{N}=\mathbf{7 8}$ & Placebo, $\mathbf{N = \mathbf { 8 4 }}$ \\
\hline $\begin{array}{l}\text { On Admission } \\
\text { Pulse rate (beats per } \\
\text { minute) }\end{array}$ & $87.27 \pm 5.96$ & $86.33 \pm 5.47$ \\
$\quad$ Systolic BP (mmHg) & $112.76 \pm 9.76$ & $113.40 \pm 10.42$ \\
$\quad$ Diastolic BP (mmHg) & $77.26 \pm 8.49$ & $79.05 \pm 7.86$ \\
$\mathbf{1}$ h after delivery & & \\
$\quad$ Pulse rate (beats per & $86.18 \pm 6.13$ & $87.07 \pm 5.08$ \\
minute) & $112.63 \pm 8.60$ & $112.83 \pm 9.72$ \\
$\quad \begin{array}{l}\text { Systolic BP (mmHg) } \\
\quad \text { Diastolic BP (mmHg) }\end{array}$ & $75.64 \pm 7.83$ & $76.21 \pm 7.14$ \\
$\mathbf{2}$ h after delivery & & \\
$\quad$ Pulse rate (beats per & $85.58 \pm 5.73$ & $84.74 \pm 4.54$ \\
minute) & $111.513 \pm 7.82$ & $111.31 \pm 8.14$ \\
$\quad \begin{array}{l}\text { Systolic BP (mmHg) } \\
\text { Diastolic BP (mmHg) }\end{array}$ & $74.52 \pm 6.74$ & $74.14 \pm 6.64$ \\
\hline
\end{tabular}

was higher than the $25.3 \%(p<0.001)$ reported by Gungorduk and colleagues [35], 22.3\% $(p<0.01)$ and $21.3 \%$ $(p<0.03)$ reported by Yang and co-workers [36] and Mirghafourvand and colleagues [30] respectively. These difference in blood loss may be as a result of the different 
Table 3 Pre delivery and post-delivery Haemoglobin/Haematocrit levels in the study and in the control group

\begin{tabular}{|c|c|c|c|}
\hline Variables & Study group, $N=78($ mean $\pm S D)$ & $\begin{array}{l}\text { Placebo group, } N=84 \\
\text { (Mean } \pm \text { SD) }\end{array}$ & $P$-value \\
\hline Blood loss at delivery (ml) & $174.87 \pm 119.83$ & $341.07 \pm 67.97$ & $<0.0001$ \\
\hline \multicolumn{4}{|l|}{ Maternal Haematocrit (\%) } \\
\hline Pre-delivery & $33.99 \pm 3.0$ & $34.01 \pm 2.92$ & 0.9658 \\
\hline 48 Hours Postpartum & $32.54 \pm 3.36$ & $31.33 \pm 2.88$ & 0.0147 \\
\hline Mean Change in Haematocrit & $3.14 \pm 0.94$ & $4.11 \pm 1.1$ & 0.0018 \\
\hline \multicolumn{4}{|l|}{ Maternal Haemoglobin (g/dl) } \\
\hline Pre-delivery & $11.66 \pm 1.00$ & $11.84 \pm 0.90$ & 0.2297 \\
\hline $48 \mathrm{~h}$ postpartum & $11.14 \pm 1.07$ & $10.45 \pm 0.96$ & $<0.0001$ \\
\hline Difference in Haemoglobin after $48 \mathrm{~h}$ & $0.94 \pm 0.43$ & $1.21 \pm 0.63$ & 0.0019 \\
\hline Platelets & $198.7 \pm 36.5$ & $203.1 \pm 43.7$ & 0.4895 \\
\hline Clothing Time & $4.5 \pm 0.9$ & $4.7 \pm 1.1$ & 0.2092 \\
\hline
\end{tabular}

Table 4 Pre-delivery and post-delivery variables in the study and control groups

\begin{tabular}{|c|c|c|c|c|}
\hline Variable & $\begin{array}{l}\text { Study group } \\
N=78, \mathrm{n}(\%)\end{array}$ & Placebo group $N=84, \mathrm{n}(\%)$ & $\mathrm{RR}(95 \% \mathrm{Cl})$ & $P$-value \\
\hline Blood loss > 500 (ml) & $4(5.13 \%)$ & $6(7.14 \%)$ & $0.71(0.38-1.79)$ & 0.5956 \\
\hline \multicolumn{5}{|l|}{ Additional interventions } \\
\hline Blood transfusion & $1(1.28 \%)$ & $3(3.57 \%)$ & $0.25(0.09-2.82)$ & 0.3496 \\
\hline Uterotonics & $3(3.85 \%)$ & $14(16.67 \%)$ & $0.24(0.12-0.96)$ & 0.007 \\
\hline \multicolumn{5}{|l|}{ Patients with side effects } \\
\hline Minor side effects: Diarrhoea & $1(1.15 \%)$ & $0(0 \%)$ & & \\
\hline
\end{tabular}

time intervals for administration of TXA. In the present study, TXA was administered within 2 min of delivery of the baby. Gungorduk and colleagues [35] documented TXA administration of 5 min while Mirghafourvand and colleagues documented $10 \mathrm{~min}$ after delivery of the anterior shoulder [30]. The WOMAN trial had recommended early administration of tranexamic acid in the management of severe bleeding following delivery. It may also be due to the time interval of assessing the blood loss and the different methods used in the estimation of blood loss for the various studies.

While some used graduated bags [28, 30], others calculated the mean blood loss volume by measuring sheets of pads from the end of delivery to $2 \mathrm{~h}$ after birth [32]. This study also incorporated the change in haematocrit after $48 \mathrm{~h}$ of delivery.

Blood loss of $>500 \mathrm{ml}$ was not significantly reduced in the study group when compared to the control group. This finding is similar to the finding made by Mirghafourvand and colleagues [30] $(p=0.14)$ but contradicted the finding noted by Gungorduk and co- workers [35] in which the reduction of blood $>500 \mathrm{ml}$ was statistically significant $(p<0.01)$. This could have been because Gungorduk et al. incorporated high risk parturient who were likely to bleed more into their study which was not the case in this study [35].This study showed that prophylactic administration of TXA after the delivery of the baby and before the delivery of the placenta reduced the need for additional uterotonics following vaginal delivery. This is consistent with the findings in most studies that compared the efficacy of TXA to placebo in reducing blood loss after vaginal delivery [28, 30, 32, 35, 37]. Although a patient needed blood transfusion in the treatment group due to primary PPH following retained placenta, but this could also have happened to either group. A similar finding was documented by Gungorduk et al. [35] However, Sentilhes et al [28] and Roy et al [32] observed that the use of TXA reduced the need for blood transfusion.

There was a statistically significant difference in the mean haematocrit and haemoglobin $48 \mathrm{~h}$ after delivery between the two groups. This was consistent in the findings of other studies [27, 29, 35-37]. There was no significant difference in the vital signs of the patients on admission, one hour and two hours postpartum between the placebo and the study groups. However, the use of TXA was associated with a small increase in the risk of minor side effects (majorly diarrhoea) in this study but this was not statistically significant. Other studies also reported minor maternal gastrointestinal side effects and were not documented as significant $[29,34,35]$. There 
were no major maternal side effects or maternal death recorded in the present study. This was also the finding by similar studies $[28,30,36,37]$ and suggests that TXA did not have any adverse maternal outcome.

The limitations are that the study was a single centre randomized controlled study, it did not evaluate the efficacy of intravenous TXA in high-risk patients. Liquor and lochia contamination of the measured blood may not have been completely avoided. In addition, the assessment of blood loss was limited to within $2 \mathrm{~h}$ of delivery.

The main strength of this study includes the internal validity and reliability of the findings, as well as external validity which makes it generalizable.

In summary, this study demonstrated that intravenous administration of TXA acid following the delivery of the baby and before delivery of the placenta reduced blood loss following vaginal delivery. It reduced the need for additional uterotonics to control blood loss. However, the incidence of primary postpartum haemorrhage and the need for blood transfusion was not significantly reduced between the two groups. Minor side effect like diarrhoea was noted but this was not statistically significant between the groups. There were no major maternal side effects, and no maternal death was recorded. Given the findings of this study, we reject the the null hypothesis. We therefore conclude that this result lays credence to the fact that intravenous TXA used to prevent primary PPH is safe and effectively reduced blood loss following vaginal delivery without increasing maternal risks and should be made available for women selected for vaginal delivery as no woman is immune to postpartum haemorrhage. Furthermore, that there is need to evaluate these findings on a larger scale for prophylactic purposes. Finally, further research is needed to evaluate the efficacy and safety of TXA in women at risk of excessive blood loss and anaemic patients in our setting and to evaluate blood loss from delivery up to $24 \mathrm{~h}$ after delivery.

\section{Abbreviations \\ TXA: Tranexamic acid; PPH: Postpartum haemorrhage; AEFUTHA: Alex- Ekwueme Federal University Teaching Hospital Abakaliki; RCT: Randomized controlled trial; AMTSL: Active management of third stage of labour; HREC: Human research and ethics committee; $\mathrm{Cl}$ : Confidence Interval.}

\section{Acknowledgements}

The authors wishes to thank the doctors, nurses, and other healthcare staff in department of Obstetrics and Gynaecology of the Alex-Ekwueme Federal University Teaching Hospital Abakaliki for their help in data collection.

\section{Authors' contributions}

FNI, LOL and VOO contributed to the study design. The analysis was made by FNI and $V O O$ with the assistance of LOL. FNI and VOO drafted the manuscript. $\mathrm{LOL}$ and $\mathrm{BID}$ revised the manuscript. All authors read and approved the final manuscript.

\section{Funding}

No funding was received.

\section{Availability of data and materials}

The data used or analyzed during the current study are included within the article. The datasets are not publicly available due to the hospital policy and personal privacy. However, the datasets are available from the corresponding author on reasonable request.

\section{Declarations}

\section{Competing interests}

The authors declare no competing interests.

\section{Ethics approval and consent to participate}

The study was approved by the Ethics Committee of the Human Research and Ethics Committee of the Alex-Ekwueme Federal University Teaching Hospital Abakaliki (FETHA/RECNOL1/2017/541). All participating patients were informed that their clinical data may be used for academic research in the future before entering into the study and signed written informed consents. The research was conducted ethically in accordance with the World Medical Association Declaration of Helsinki.

\section{Consent for publication}

Not applicable.

\section{Conflict of interest}

There was no conflict of interest in this study to declare.

\section{Author details}

${ }^{1}$ Alex-Ekwueme Federal University Teaching Hospital, Abakaliki, Nigeria.

${ }^{2}$ Institute of Health Policy, Management and Evaluation, University of Toronto, Toronto, ON M5T 3M6, Canada.

Received: 3 June 2021 Accepted: 29 December 2021

Published online: 03 March 2022

\section{References}

1. Ajenifuja KO, Adepiti CA, Ogunniyi SO. Postpartum haemorrhage in a teaching hospital in Nigeria: a 5-year experience. Afr Health Sci. 2010;10(1):71-4.

2. AbouZahr C. Ante partum and postpartum haemorrhage. In: Murray CJ, Lopez AD, editors. Health dimensions of sex and reproduction, vol. 172. Boston: Harvard Uni Press; 1998. p. 4.3.

3. Ripley DL. Uterine emergencies: atony, inversion, and rupture. Obstet Gynecol Clin North Am. 1999;26:419-34.

4. Ezegwui HU, Onoh RC, Ikeako LC, Onyebuchi A, Umeora OUJ, Ezeonu P. Investigating maternal mortality in a public teaching hospital, Abakaliki, Ebonyi State Nigeria. Ann Med Health Sci Res. 2013;3(1):75-80.

5. de Visser SM, Woiski MD, Grol RP, et al. Development of a tailored strategy to improve postpartum hemorrhage guideline adherence. BMC Pregnancy Childbirth. 2018;18:49. https://doi.org/10.1186/ s12884-018-1676.

6. Sentilhes L, Winer N, Azria E, Sénat MV, Le Ray C, Vardon D, et al. Groupe de recherche en obstétrique et gynécologie. Tranexamic acid for the prevention of blood loss after vaginal delivery. N Engl J Med. 2018;379(8):731-42

7. World Health Organization. Reducing the global burden: Postpartum haemorrhage. 2008. Available at:https://www.who.int/maternal_ child_adolescent/documents/newsletter/mps_newslette r_issue4.pdf. Accessed on $7^{\text {th }}$ August 2017.

8. The Prevention and Management of Postpartum Haemorrhage. Report of technical working group, Geneva 3-6 July 1989. Geneva: World Health Organisation; 1990. Available at:https://apps.who.int/iris/bitstream/ handle/10665/61409/WHO_MCH_90.7.pdf?sequence=1\&isAllowed=y.

9. Elbourn DR, Pendriville WJ, Carroli G, Wood J, McDonald S. Prophylactic use of oxytocin in third stage of labour. Cochrane Database syst Rev. 2001;4:CD001808.

10. Bias JM, Eskes M, Bonsel GJ, Bleker OP. Postpartum haemorrhage in nulliparous women: incidence and risk factors in low and high-risk women. 
A dutch populationbased cohort study on standard and severe postpartum haemorrhage. Eur J Obstet Gynecol Reprod Biol. 2004;115:166-72.

11. Magnann EF, Evans S, Chauhan SP, Lanneau G, Fisk AD, Morrison JC. The length of third stage of labor and the risk of postpartum haemorrhage. Obstet Gynecol. 2005;105:2903.

12. Corwin EJ, Murray-Kolb LE, Beard JL. Low haemoglobin level is a risk factor for postpartum depression. J Nutr. 2003;133:4139.

13. Lalonde A. Postpartum hemorrhage today: ICM/FIGO initiative 20042006. Int J Gynaecol Obstet. 2006:94(3):243-53.

14. Sentilhes L, Daniel V, Darsonval A, Deruelle P, Vardon D, Perrotin F, et al. Study protocol. TRAAP - TRAnexamic Acid for Preventing postpartum hemorrhage after vaginal delivery: a multicenter randomized, doubleblind, placebo-controlled trial. BMC Pregnancy Childbirth. 2015;15:135.

15. Goffinet F, Mercier F, Teyssier V, Pierre F, Dreyfus M, Mignon A, Carbonne B, Lévy G. Groupe de travail des RPC sur l'HPP postpartum haemorrhage: recommendations for clinical practice by the CNGOF. Gynécol Obstét Fertil. 2005;33:268-74.

16. Woman trial collaborators. Effect of early tranexamic acid administration on mortality hysterectomy, and other morbidities in women with postpartum haemorrhage (WOMAN): an international, randomised, doubleblind, placebo-controlled trial. Lancet. 2017;389:2105-16.

17. Cortet M, Deneux-Tharaux C, Dupont C, Colin C, Rudigoz R-C, BouvierColle $\mathrm{M}-\mathrm{H}$, et al. Association between fibrinogen level and severity of postpartum haemorrhage: secondary analysis of a prospective trial. $\mathrm{Br} J$ Anaesth. 2012;108:984-9.

18. Charbit B, Mandelbrot L, Samain E, Baron G, Haddaoui B, Keita H, PPH Study Group, et al. The decrease of fibrinogen is an early predictor of the severity of postpartum hemorrhage. J ThrombHaemost. 2007;5(2):26673. https://doi.org/10.1111/j.15387836.2007.02297.

19. Ducloy-Bouthors AS, Jude B, Duhamel A, Broisin F, Huissoud C, KeitaMeyer $\mathrm{H}$, et al. High-dose tranexamic acid reduces blood loss in postpartum haemorrhage. Crit Care Lond Engl. 2011;15:R117.

20. Begley CM, Gyte GML, Devane D, McGuire W, Weeks A. Active versus expectant management for women in the third stage of labour. Cochrane Database Syst Rev. 2015;3:CD007412.

21. Westhoff G, Cotter AM, Tolosa JE. Prophylactic oxytocin for the third stage of labour to prevent postpartum haemorrhage. Cochrane Database Syst Rev. 2013;10:CD001808.

22. Deneux-Tharaux C, Sentilhes L, Maillard F, Closset E, Vardon D, Leperca $J$, et al. Effect of routine controlled cord traction as part of the active management of the third stage of labour on postpartum haemorrhage: multicentre randomised controlled trial (TRACOR). BMJ. 2013;346:f1541.

23. Hofmeyr GJ, Abdel-Aleem H, Abdel-Aleem MA. Uterine massage for preventing postpartum haemorrhage. Cochrane Database Syst Rev 2013;7:CD006431.

24. Novikova N, Hofmeyr GJ, Cluver C. Tranexamic acid for preventing postpartum haemorrhage. Cochrane Database Syst Rev. 2015;6:CD007872. https://doi.org/10.1002/14651858.CD007872.pub3.

25. Ker K, Edwards P, Perel P, Shakur H, Roberts I. Effect of tranexamic acid on surgical bleeding: systematic review and cumulative meta-analysis. BMJ. 2012:344:e3054

26. CRASH-2 trial collaborators, Shakur H, Roberts I, Bautista R, Caballero $J$, Coats T, et al. Effects of tranexamic acid on death, vascular occlusive events, and blood transfusion in trauma patients with significant haemorrhage (CRASH-2): a randomised, placebo-controlled trial. Lancet. 2010;376:23-32

27. Matteson KA, Rahn DD, Wheeler TL 2nd, Casiano E, Siddiqui NY, Harvie HS, et al. Nonsurgical management of heavy menstrual bleeding: a systematic review. Obstet Gynecol. 2013;121:632-43.

28. Sentilhes L, Lasocki S, Deruelle P, Perrotin F, Goffinet F, Deneux-Tharaux C. Tranexamic acid for the prevention and treatment of post-partum hemorrhage. Brit J Anaesth. 2015;114(4):576-87.

29. Hellgren M. Hemostasis during normal pregnancy and puerperium. Semin Thromb Hemost. 2003:29:125-30

30. Mirghafourvand M, Mohammad-Alizadeh S, Abbasali-Zadeh F, Shirdel $M$. The effect of prophylactic intravenous tranexamic acid on blood loss after vaginal delivery in women at low risk of postpartum haemorrhage: a double-blind randomised controlled trial. Aust N Z J Obstet Gynaecol. 2015;55(1):53-8.

31. Charan J, Biswas T. How to calculate sample size for different study designs in medical research. Indian J Psychol med. 2013;35(2):121-6.
32. Roy P, Sujatha MS, Bhandiwad A, Biswas B. Role of tranexamic acid in reducing blood loss in vaginal delivery. J Obstet Gynecol India. 2016:66(S1):S246-50.

33 Thornton JA, Saynor R, Schroeder HG, Taylor DG, Vere D. Estimation of blood loss with particular reference to cardiac surgery. Description of a method. Brit J Anaesth. 1963;35:91.

34. Greenberg EM. The fourth stage of labor; an account of the physiology and clinical aspects of the postpartum uterus during the first postplacental hour. Am J Obstet Gynecol. 1946:52(5):746-55 PMID: 20273854.

35. Gungorduk K, Asıcıoğlu O, Yıldııım G, Ark C, Tekirdağ Al, Besımoglu B. Can intravenous injection of tranexamic acid be used in routine practice with active management of the third stage of labor in vaginal delivery? A randomized controlled study. Am J Perinatol. 2013;30:407-13.

36. Yang $\mathrm{H}$, Zheng $\mathrm{S}$, Shi $\mathrm{C}$. Clinical study on the efficacy of tranexamic acid in reducing postpartum blood loss: a randomized, comparative, multicenter trial. Zhonghua Fu Chan Ke Za Zhi. 2001;36:590-2.

37. Heesen M, Böhmer J, Klöhr S, Rossaint R, van de Velde M, Dudenhausen JW, et al. Prophylactic tranexamic acid in parturients at low risk for post-partum haemorrhage: systematic review and meta-analysis. Acta Anaesthesiol Scand. 2014;58:1075-8.

\section{Publisher's Note}

Springer Nature remains neutral with regard to jurisdictional claims in published maps and institutional affiliations.

Ready to submit your research? Choose BMC and benefit from:

- fast, convenient online submission

- thorough peer review by experienced researchers in your field

- rapid publication on acceptance

- support for research data, including large and complex data types

- gold Open Access which fosters wider collaboration and increased citations

- maximum visibility for your research: over 100M website views per year

At BMC, research is always in progress.

Learn more biomedcentral.com/submissions 